\title{
Naturalistic vs Supernatural Explanations: "Charting" a Course away from a Belief in God by Utilizing Inference to the Best Explanation
}

\author{
Randall S. Firestone \\ Department of Philosophy, El Camino College, Torrance, CA, USA \\ Email: Randyfirestone@verizon.net
}

Received 28 May 2014; revised 2 July 2014; accepted 13 July 2014

Copyright (C) 2014 by author and Scientific Research Publishing Inc.

This work is licensed under the Creative Commons Attribution International License (CC BY).

http://creativecommons.org/licenses/by/4.0/

(c) (i) Open Access

\section{Abstract}

The article critiques the seven major arguments supporting a belief in God. The arguments are presented as Inferences to the Best Explanation with the use of charts. The charts graphically demonstrate that naturalistic explanations are being ignored by the theist, who favors inherently unverifiable supernatural explanations over naturalistic ones. The paper also discusses why metaphysical beliefs should not be trusted, and how such beliefs differ from scientific beliefs. The paper concludes that the arguments for the existence of God fail because the naturalistic explanations are the best explanations and should be accepted over the supernatural explanation of God. To the extent that the charting of all seven arguments is new, it should be a helpful explanatory tool, especially for students.

\section{Keywords}

God, Religion, Inference to the Best Explanation, Arguments for God, Problems with Arguments for God, Naturalistic Explanations, Supernatural Explanations, Philosophy of Religion, Cosmological Argument, Teleological Argument, Fine-Tuning Argument, Reliability of Scripture, Miracles, Religious Experience, Ontological Argument

\section{Introduction}

This paper will look at seven major arguments supporting a belief in God-the Cosmological, Teleological, and Fine-Tuning Arguments, in addition to the Argument from the Reliability of Scripture, Argument from Miracles, 
Argument from Religious Experience, and one version of the Ontological Argument ${ }^{1}$. It is the position of this paper that the manner in which philosophical discussions regarding the existence of God have proceeded to date has tended to be unfair because naturalistic explanations have not been given their due. This "due" is an actual preference for natural explanations, if they exist, over supernatural ones. When the arguments for God's existence are presented as Inferences to the Best Explanation, the theistic arguments are exposed for what they dofavor inherently unverifiable supernatural explanations over naturalistic ones.

I will demonstrate this with summaries of these seven arguments for God and the alternative naturalistic explanations available, and will additionally introduce charts for all seven of the arguments. To the extent that the charting of all seven arguments is new, it is my hope that it will prove to be a helpful explanatory tool, especially for students. These charts will display how each of the arguments for God can be couched as an Inference to the Best Explanation, and will graphically highlight the ignored or discounted naturalistic choices.

It is not the intention of this article to give an exhaustive analysis of each of the above arguments for God, as that would require a book-length treatment. My purpose, rather, is to show that in each case, naturalistic explanations are available and are tacitly dismissed and ignored, or at least discounted and minimized, while a supernatural explanation for which there is no proof, nor any way to test, confirm, or verify, is accepted over such naturalistic explanations. In each case, however, it is those naturalistic explanations which are the best explanation and should be accepted.

\section{Why Naturalistic Explanations Should Be Accepted over Supernatural Ones}

How do we know what exists in the world? The simple answer is that it is through the use of our senses. Without senses, it is difficult to see how we could know anything about the external world, or even if anything existed beyond ourselves. The problem we face when it comes to issues such as whether God exists is that a supernatural or metaphysical entity such as God cannot be known by our sensory experiences of the world, as Immanuel Kant, a believer in a Supreme Being, has so aptly affirmed ${ }^{2}$. Our senses do not directly reveal whether God exists, whether we have souls that can survive our physical death, whether karma exists to ensure moral justice, or whether there is a Heaven or a Hell. Metaphysical claims are by their very nature unverifiable in that you cannot devise a test or experiment to confirm the presence of a metaphysical entity such as God, nor go to visit a metaphysical place, such as Heaven or Hell.

Furthermore, accurate predictions cannot be made about what alleged metaphysical things will do in the future, or when metaphysical events will occur. For example, even if you believe that there is a God who creates miracles, you still cannot predict when or where a miracle will occur. Those who have made such predictions have been notoriously inaccurate, just as people have similarly predicted a multitude of apocalypses which have not occurred.

We can contrast metaphysical beliefs with scientific claims. Scientists have developed methods to help ensure that their conclusions accurately reflect the way the world actually is and functions. Science starts out with a hypothesis, which is a proposed statement or explanation about what scientists believe is true about the world. This claim is then tested, and based on the results of the tests the hypothesis is either accepted, rejected or modified. Predictions are made and then tested to see if they hold true. If extensive testing supports the hypothesis, it is then considered a workable theory or scientific fact.

In general, science operates on what is called the Argument or Inference to the Best Explanation. Scientists seek to explain how the world works, examine the possibilities, and favor the theory that best matches with the results and evidence derived from testing. This will be the best explanation.

Scientists and philosophers have developed several criteria to help them evaluate whether a hypothesis or

${ }^{1}$ One of the arguments for God I have chosen not to discuss in this paper are the various conceptions of the Moral Argument. One version of the Moral Argument claims that because there is a moral right and wrong then there must be a God for without a God there could be no absolute or objective right and wrong, while another version claims that because most people are convinced some actions are morally better than others that there must be something maximally good, and that maximal goodness is what we call God. These arguments suffer from both faulty logic, and also a failure to acknowledge that there are many secular moral theories, such as Utilitarianism and Kant's duty ethics, which provide a basis to conclude some actions are right or wrong. As such, reasonable alternatives that do not appeal to the supernatural are being ignored, as is true of the other Arguments for God that this paper will examine.

${ }^{2}$ Kant states as follows: "Metaphysics has to do not only with concepts of nature, which always find their application in experience, but also with pure rational concepts, which never can be given in any possible experience. Consequently the objective reality of these concepts (viz., that they are not mere chimeras), and the truth or falsity of metaphysical assertions, cannot be discovered or confirmed by any experience.” (Kant, 1783: p. 804). 
claim is true ${ }^{3}$. These include internal consistency, testability, fruitfulness in being able to successfully predict new phenomena, a wide enough scope to account for and predict many and diverse phenomena, simplicity (in part because the more complex the theory the more assumptions that can be wrong), and consistency with accepted scientific and other knowledge. These considerations have proven themselves to be successful guides to scientific conclusions which accurately portray the world.

Employment of these criteria, however, does little to support metaphysical claims, so there is no reason to have confidence that these claims are actually true. Furthermore, metaphysical claims seem to contradict an assumption of science that has proven to be both useful and true time and time again, namely, that there are natural causes which can explain the events and occurrences in the world. Virtually all of our vast scientific progress has been based on this belief. If scientists had assumed that the causes were supernatural or metaphysical, they would not have engaged in their search for physical causes. Yet it is this search for physical causes that has continued to supply the answers to the many mysteries and questions that scientists have posed. Indeed, the overwhelming evidence indicates that our world and everything in it can be explained by physical forces, and this assumption has allowed scientific knowledge to grow exponentially, and to supply answers to incredibly sophisticated and complex questions. What is often not noticed is that the lack of any direct or strong evidence of metaphysical entities coupled with the abundance of evidence that the physical world can be explained with physical, natural explanations present the theist with a mountain of evidence against their metaphysical beliefs.

Not only are metaphysical claims unverifiable, they also appear to be unfalsifiable. No matter how strong or even overwhelming the evidence against the belief, and no matter how lacking the evidence for the belief, the believer will not let that evidence, or lack thereof, ever count as enough to overturn their belief ${ }^{4}$. As such, the evidence has become irrelevant for their belief. Indeed, those people who have unfalsifiable beliefs are more concerned with maintaining their beliefs than in actually finding the truth.

For example, no matter how chaotic and destructive the universe is, and no matter how miserable its inhabitants may be, the theist will claim that this is still somehow consistent with a perfect, loving, and just God. Likewise, no matter how overwhelming the evidence is that the prayers of good people go unanswered, the believer will not let this count against their belief in a good God. We hear such comments as "It is not for us to know God's plans" or "We as limited and finite beings cannot begin to understand God's purposes for all the terrible things that occur, nor God's non-action in the face of evil.” For the theist, the evidence has become irrelevant.

It is the position of this paper that we should always go with a scientific explanation over a metaphysical one because metaphysical entities and forces are beyond our abilities to sense, unconfirmable by skeptical others who are with us, and beyond our predictive abilities. Indeed, the claim that metaphysical entities or forces exist is untestable, unmeasurable, unverifiable, and unfalsifiable.

We should notice how scientific conclusions are much more closely scrutinized than most of our other beliefs, including our religious metaphysical beliefs, because alternatives are supposed to be considered, as are possible problems with a hypothesis. Further, other scientists are encouraged to verify or refute the findings by conducting their own independent research. The rigors of science are well summarized by science writer Michael Shermer:

In science we have built-in self-correcting machinery. Strict double-blind controls are required in experiments, in which neither the subjects nor the experimenters know the experimental conditions during the data-collection phase. Results are vetted at professional conferences and in peer-reviewed journals. Research must be replicated in other laboratories unaffiliated with the original researcher. Disconfirmatory evidence, as well as contradictory interpretations of the data, must be included in the paper. Colleagues are rewarded for being skeptical. Extraordinary claims require extraordinary evidence (Shermer, 2006: p. 36).

\footnotetext{
${ }^{3}$ For a more thorough discussion of scientific methodology in general, and of these criteria in particular, see (Schick Jr. \& Vaughn, 2011: pp. 161-181).

${ }^{4}$ Some theists claim that science also suffers from unfalsifiability in that it assumes that our senses put us in touch with an external world, and there is no non-circular way to verify or falsify this claim. Although it is undoubtedly true that science must make this basic assumption, it is important to distinguish the very real differences in the kind of assumptions made by science and religion. Nobody could function without assuming that there is a physical world and our senses supply us with information about that world. No sane person really doubts this. The assumption that metaphysical things exist (which are beyond the senses) is not a necessary assumption for everyday living. Moreover, science demands that claims of the existence of physical objects are verifiable and can be falsified by lack of evidence of their existence, while there is no way to verify that metaphysical objects such as God, souls, and Heaven and Hell exist, nor will the theist allow this lack of evidence to count against the belief in such things. Furthermore, scientific assumptions have been able to make accurate predictions about the future while metaphysical beliefs have not been able to do so. For a good discussion of this point, see (Murray, 2010: pp. 168-179).
} 
Metaphysical claims are indeed extraordinary as they are beyond our sensory perception. Such "extraordinary claims require extraordinary evidence" but are unable to supply such evidence because there is no compelling or direct evidence that non-physical beings, forces, or places exist-if any evidence at all ${ }^{5}$. Naturalistic explanations which are consistent with science, and which do not rely on forces that cannot be measured or sensed, always have a greater likelihood of truth than corresponding supernatural metaphysical claims because they do not assume the existence of a non-physical entity.

To understand why science does not opt for a supernatural explanation and in a sense always presumes against such an explanation and in favor of a naturalistic one, we need to notice the following related nine points that militate against going with a supernatural explanation.

First, there is no direct or compelling evidence that anything metaphysical exists, and arguably there is no evidence at all. Any immaterial entity is beyond our ability to sense, to test, to predict, and to verify its existence.

Second, not only do we currently have no evidence of the existence of metaphysical things, it seems that there is no possibility to ever get such evidence since our physical senses do not have access to anything that is not physical.

Third, it is a puzzle how a metaphysical being could actually be anything. How could it have any attributes at all without a physical body? We know that our personalities and dispositions are tied to our human brain and body, so how could an immaterial entity have a personality or disposition, or any other attribute?

Fourth, even if metaphysical things exist, since we have no access to them we could not know anything about them $^{6}$. As such, we could not know their attributes. It follows then that we could not know if there exists an entity which is perfectly good and just, or is all-powerful or all-knowing.

Fifth, a metaphysical creator such as God would have to be conscious in order to create the world, but where does consciousness come from if not a physical brain? We know that if we severely damage certain parts of the human brain then there are corresponding thoughts that one will be unable to have. For instance, if one severely injures one part of their brain, then they will lose the ability to make moral decisions, while if they develop serious deterioration of another part of their brain then their memories will be gone forever-as happens with some elderly people who develop Alzheimer's. Given how our consciousness is tied to our physical brain, how would a non-physical entity without a physical brain be able to think? We have no explanation for this, and our experiences lead us to believe that this is likely impossible.

Sixth, how would God be able to perceive or sense the world if he did not have a physical body with sensory organs such as eyes that can see and ears that can hear?

Seventh, how could a God create or interact with the world without a physical body to create things and put them together? God would have no hands, no arms, no legs, no fingers, etc. with which to fashion a world, or anything at all.

Eighth, and more fundamentally, how could a metaphysical entity, something fully non-physical, have any causal abilities or effects on a physical world? Specifically, how could a god, who is allegedly immaterial and without size, mass, density, shape, energy, etc., fashion a star, or move a planet? If a bug cannot move a person due to its small size, how could something with no physicality whatsoever move anything, let alone create a vast universe?

\footnotetext{
${ }^{5}$ Now it could be argued that, similar to science, belief in supernatural things such as a god is reasonable in that it explains things that we observe in the world. So, for example, scientists posited the presence of gravity to explain why our bodies are held down on earth and not flying off into space, and posited black holes to explain why there were wobbles in orbits of stars that were close to areas of darkness. It could be argued that in much the same way, a supernatural God is posited to explain things about the natural world, such as why there is a big universe that appears in some respects organized and whose physical laws are fit or fine-tuned to allow for life. However, as previously discussed, such an argument to the supernatural is very unlike what science does, and in fact such an approach would have severely inhibited scientific progress. Scientists did not conclude that supernatural powers or Gods were holding people onto the earth, or that Gods were making the orbits of stars wobble. If scientists had done so, there would have been no knowledge obtained about the true natures of gravity and black holes. Quite the contrary, science looked for natural explanations because there is no evidence that anything exists which is not in the form of matter or energy. Likewise, we would have made little progress in treating the mentally ill if we just accepted that their behavior was attributable to invisible, evil demons that possessed them instead of due to a psychological and/or biological disorder.

${ }^{6}$ Immanuel Kant admitted as such when he called God a thing in itself, and then said that humans cannot know or say anything about things in themselves. Specifically, Kant stated "that the Supreme Being is quite inscrutable and even unthinkable in any definite way as to what he is in himself. We are thereby kept, on the one hand, from making a transcendent use of the concepts which we have of reason as an efficient cause (by means of the will), in order to determine the Divine Nature by properties, which are only borrowed from human nature *..” (Kant, 1783: pp. 817-818). Kant makes it clear that God is a thing in itself when he states that "an immaterial being, a world of understanding, and a Supreme Being (all mere noumena), because in them only, as things in themselves...” and then concludes that we cannot know about things in themselves because they are beyond our experience and "reason does not however teach us anything concerning the thing in itself" (Kant, 1783: pp. 815,819).
} 
Faced with all of these problems with the concept of a non-physical God, it may not be surprising that at least one philosopher, the $17^{\text {th }}$ Century philosopher Baruch Spinoza, sought to overcome these challenges by asserting that God must be physical ${ }^{7}$. This assertion, however, is also fraught with problems that most theists have wished to avoid. For example, since physical objects deteriorate and die or otherwise go out of existence, it would seem that a physical God would likewise die, and a dead God would hardly seem to be an embodiment of perfection.

There is an additional reason to distrust the belief in metaphysical entities. The reason that ancient peoples were so prone to believe in them is because they could not explain many things that occurred in the natural world. Without a supernatural explanation, they would have had no explanation at all. This is what scientist Richard Dawkins calls the "God of the Gaps" in that God was the answer which filled in the gaps in knowledge, i.e., to explain whatever what was then unexplainable (Dawkins, 2006: pp. 144-161). However, today most ancient metaphysical beliefs, such as the beliefs in animism and polytheism, are readily dismissed by educated people because we now have naturalistic explanations. Moreover, just because science still does not have all the answers it does not follow that immaterial entities exist, especially since we know that we have been able to explain so many earlier puzzling events with naturalistic explanations, and we can expect we will be able to explain even more in the future.

Before proceeding to the arguments for God, we need to pay special attention to the scientific criteria of simplicity_-going with the simplest explanation that can fully explain the event or action. Philosophers and scientists have long utilized a version of this principle called Ockham's Razor, which is usually summarized: “Don’t multiply entities beyond necessity.” For example, I can account for earthquakes, hurricanes, and the eruption of volcanoes with naturalistic explanations, but I could also account for these natural disasters by claiming that 12 invisible leprechauns are causing them. Although this second explanation is logically possible, I have multiplied entities, namely, invisible leprechauns, which I must now show both exist and have created those natural disasters. A naturalistic explanation seems simpler because we know through observation that the physical things in nature both exist and behave in certain ways, but we have no strong evidence of the existence of invisible leprechauns. It seems better to stick with the simpler explanation that can account for the effect. In other words, there is no reason to assume that invisible beings or powers caused or created something when there is a simpler explanation available for which we have strong evidence.

Ockham's Razor can be more completely expressed as follows: Don't propose the existence of something and thereby add another level of questions or analysis unless 1) it is needed and therefore really helps you, 2) it is supported by the evidence, and 3) it does not leave you with the same basic kinds of unanswered questions, or even more complex or difficult ones. Metaphysical entities seem to fail in all regards here: First, a belief in them is not needed because we have naturalistic explanations for most things. Second, there is little if any evidence for metaphysical entities, forces, or places. Third, a belief in the metaphysical introduces a host of unanswered and seemingly unanswerable questions as not only their attributes but also their very existence cannot be either known or verified by our senses. Thus we are left with even more questions, and certainly more difficult questions, than we started with.

In summary, when trying to understand things about the world, we are looking for the simplest explanation for which there is evidence, and in science we expect that the conclusion/explanation can be tested and verified. The problem with metaphysical claims is that there is no evidence that can be tested and verified, and therefore there are strong reasons to go with naturalistic explanations if they are available. Moreover, we simply have no good reason to believe that something non-physical exists, and even if there were such metaphysical entities, it seems impossible for human beings to know anything about them as we have no access to them either through our senses or otherwise. As such, if we care about the evidence and arriving at the truth, we should not go with supernatural explanations to explain events in our world—especially if there are naturalistic explanations available. As we shall see in the next section, there are naturalistic explanations available regarding each of the seven major arguments for God's existence.

\section{Charting the Arguments for God}

The Inference to the Best Explanation is a device people use every day, and a hallmark of science. It looks at the alternative explanations available, and asks us to find the one that best fits the facts. If we care about the truth, it

\footnotetext{
${ }^{7}$ Specifically, Spinoza writes as follows: "I do not know why matter should be unworthy of the divine nature*.. Therefore in no way whatever can it be asserted that God suffers from anything, or that substance extended, even if it be supposed divisible, is unworthy of the divine nature..." (Spinoza, 1677: p. 541).
} 
would make no sense to do otherwise.

We should note that all of the arguments for God's existence could be put into standard argument form which consists of premises and a conclusion. There are two main ways to attack the conclusion of an argument: 1) Show that one or more of the premises are likely to be untrue, and therefore the foundation for the conclusion is shaky, or 2) show that even if the premises are true, the conclusion does not necessarily follow from the premises. The arguments for God fail on both accounts. First, even if we take the premises to be true, the conclusion that God must exist does not necessarily follow because there are always alternative naturalistic explanations. Second, it is often the case that at least one of the premises is likely to be untrue.

Let us take the teleological argument for an example. We could set out the argument as follows:

1) The universe is organized, both as a whole and in its smaller parts.

2) Such organization needs an explanation.

3) The explanation of the organization is God, who is the organizer.

Such an argument has problems on two levels: First, there are naturalistic possibilities that can explain any organization that there is, so even if the premises are true the conclusion does not necessarily follow. Second, premise one is debatable and challengeable because the world in many respects appears quite chaotic and disorganized instead of organized.

\subsection{The Cosmological Argument}

Why is there a Universe? Why is there something and not nothing? In fact, why is there not only something, but so many somethings? How did the vast number of stars, planets, and galaxies come into existence? It seems these questions need an explanation, and there are three prime candidates ${ }^{8}$.

\section{Possible Explanations for the Universe}

\section{God or gods created}

the universe.
The universe arose out of nothing.
The universe is eternal.

The first explanation is the conclusion reached by the Cosmological Argument. The next two explanations are naturalistic - that the universe arose out of nothing or is eternal. As to the second alternative, there are several scientific theories which are supported by some of the leading scientists in the world about the possibility if not likelihood that our vast universe sprung forth out of either a vacuum, which is close to nothingness, or out of complete nothingness. For example, in his latest book co-authored with fellow physicist Leonard Mlodinow, world renowned cosmologist Stephen Hawking concluded that that the universe likely arose out of nothing ${ }^{9}$.

According to M-theory, ours is not the only universe. Instead, M-theory predicts that a great many universes were created out of nothing. Their creation does not require the intervention of some supernatural being or god. Rather, these multiple universes arise naturally from physical law (Hawking \& Mlodinow, 2010: p. 8).

Other scientists, such as theoretical physicists Paul Steinhardt of Princeton University and Neil Turok of the University of Cambridge, believe that the third possibility may be correct-that the universe may have always been here and does not have a beginning. This theory holds out the possibility that there have been numerous big bangs, and numerous expansions and contractions of the universe. What we see now may be only the most recent manifestation of an eternal process (Steinhardt \& Turok, 2002). If this "cyclic model” of the universe is true and the universe is eternal, then the universe could not have had a creator.

We should note something at the outset: All of the choices seem to have a problem. If we go with the first explanation of God as the creator, then we are left with the question of who or what created God, or how could God exist forever; if we go with the second explanation that the universe arose out of nothing, then we are left asking why nothing has the property of being able to create a universe; and if we go with the third explanation that the universe is eternal, then we are left with the question of how anything could just have been there forever

\footnotetext{
${ }^{8} \mathrm{~A}$ seeming fourth possibility is that the universe created itself. However, this answer actually begs the question because if something created itself then it was already there to create itself, so we still haven't answered the question of how it got there in the first place. As such, something creating itself is actually a logical impossibility and therefore not a real explanation at all.

${ }^{9}$ In addition to Stephen Hawking and Leonard Mlodinow, other leading theoretical physicists/cosmologists who have reached a similar conclusion include Arizona State Professor Lawrence Krauss, and Tufts Professor Alexander Vilenkin.
} 
without a creator or beginning. It seems we will have to settle on one of the explanations as a brute fact, which means we will have to accept one of the explanations without asking any more "whys" as in "why is this the case?" However, having said that we must rely on a brute fact does not imply that one or more of the explanations are not either more or less probable than the others. So is one of the explanations less probable? The God explanation seems to fall into this category for the following reasons.

First, the God explanation relies on the supernatural, but we have no evidence to support that anything supernatural and immaterial exists.

Second, not only do we have no evidence or proof of a supernatural being, but if we go with the Christian conception of God then we also have no evidence or proof of an all-good, all-powerful, and all-knowing perfect being, nor of a being which has a non-physical consciousness that could somehow create one or many universes.

Third, if we go with the first choice of God as the creator of the universe then we are left with the following question: How did God come into existence? In fact, we should notice that going with the first possible explanation of God as the creator of the universe has not really helped us at all because God now is part of the somethings that needs explaining. As Derek Parfit states, "an appeal to God cannot explain why the universe exists, since God would himself be part of the Universe, or one of the things that exist.” (Parfit, 1998). Moreover, we can see from the chart below that if we posit a god as the creator of the universe we are left with virtually the same possibilities as we started with, so we have really made no progress, and have violated Ockham's Razor to not multiply entities unless it really helps us and the existence of the new entities is supported by the evidence.

Possible Explanations for God

\section{Another God Created God.}

God arose Out of Nothing.

\section{Possible Explanations for God}

\section{God is Eternal.}

Of the three possible explanations for God, nobody goes with the first choice for obvious reasons. If the explanation for the God who created our universe, which we can call God 1, is an even more powerful God 2 who created God 1, then the explanation for God 2 would be God 3, and for God 3 would be God 4, etc. We will be left with an infinite regress of an infinite number of gods. This would be as severe a violation of Ockham's Razor that one could possibly imagine because we have "multiplied" or proposed the existence of an infinite number of entities/gods for which there is no proof, and we have naturalistic explanations which do not require us to multiply or postulate the existence of any entities or gods at all.

What about the choice that God arose out of nothing? Initially we should note that theists do not support or favor this choice. Further, this explanation suffers from at least two problems. First, no scientist has any idea of how a conscious and perfect God could come out of nothingness. Contrast this with the scientific support for the idea that the universe could naturally have come from nothing. Second, if we think that something could come from nothing, then why not just propose that the universe came from nothing, and thereby not multiply or add the entity of God in violation of Ockham's Razor? Since we are sure there is a universe, but have no such surety when it comes to a metaphysical creator, it is of little help to postulate a creator who could arise out of nothing when the universe could have done so.

The third choice is the alternative chosen by theists—-that God is eternal. But again this violates Ockham's Razor for if something could be eternal, then why not conclude that the universe is eternal and not add another entity, namely God, whose existence is unproven. In fact, it seems that the Christian is in a particularly weak position to challenge the third alternative that the universe is or might be eternal because the Christian believes that something could be eternal, namely, God.

We might also recognize that an eternal universe is consistent with our experiences of the world which reveal that for every effect there must be a cause. This is considered a natural law, and upon which much of modern science is based. Belief in an eternal God violates this natural law because it states that there was no cause for God since God has just always been there and is therefore uncaused. Moreover, as we have never witnessed the creation of universes, it remains a possibility that the universe has always existed — even if it was in very different states before arriving at its current form, such as having been a vacuum, or maybe having gone through numerous expansions, contractions, and big bangs in the past.

So how could there be an eternal universe of things? We should notice that this question and the cosmological argument itself presume that the universe needs an explanation. In other words, the default position is that we should expect there to be nothing, so if there is something it needs an explanation. But maybe we have it wrong. 
If we found a universe with nothing, would it not be just as legitimate a question as to why that universe had nothing instead of something? Suppose that in the future scientists find evidence of ten other universes, and nine of them have things in them, while the tenth universe has nothing in it. In such a case, would not the most poignant question be why this tenth universe had nothing instead of something? As such, it may be the case that the default position should be a universe with things in it, not a vacant universe, and a universe with nothing in it should be the fact that demands an explanation ${ }^{10}$.

Indeed, instead of asking why there is something and not nothing, we might notice that there are many possibilities for how the universe could be: Perfectly moral or perfectly evil; perfectly organized or fully chaotic; perfectly full, i.e. consisting of an infinite number of things, or null, i.e. nothing - and everything in between. Nothingness is just one possibility, so statistically would not be expected. A "mediocre" universe, such as our own, with some organization and some seemingly undesigned chaos, with many things but also vast open spaces of nothingness, and with some morality and some immorality, would seem to be the most likely and arguably simplest explanation, as there is no reason to expect one of the extremes would be true. Such mediocrity does not seem to require a god as its creator.

In summary, if we apply Ockham's Razor to the Cosmological Argument, then why assume that there is a god who created the universe when there are naturalistic explanations for the origin of the universe, and we would be left with just as big an unanswerable question, namely, how did God, with such power and consciousness, come into existence? If God can be eternal or could come from nothing, then why not just conclude the universe is eternal or could come from nothing, and then we do not have to add a metaphysical entity for which we have no proof?

\subsection{The Teleological Argument a.k.a. the Argument from Design}

Let us next look at the Teleological Argument as an Argument to the Best Explanation. The most famous version of this argument is Paley's watch analogy. Paley argued that just as if we found a watch we would conclude it had a maker/creator because of its organized complexity for a purpose, we should likewise conclude that the universe has a maker/creator due to its organized complexity. Paley states that "every indication of contrivance, every manifestation of design, which existed in the watch, exists in the works of nature; with the difference, on the side of nature, of being greater and more, and that in a degree which exceeds all computation." (Paley, 1802).

The problem with this version of the teleological argument is that it is not only based on an analogy, but a seemingly very weak one. All analogies are one-sided arguments that ignore the differences between the two things being compared, and in this case the two things could not be more different. After all, it is comparing watches to universes, immensely different things. Moreover, we have experience with watches, their creation and purpose, and we know that watches do not naturally appear in nature so must have a maker, while, on the other hand, we have no experience with the creation of universes, the universe has no clear and obvious purpose, and the universe and everything in it is natural and a part of nature so does not necessarily require a creator, unlike a human artifact such as a watch.

In Paley's defense, we should note that until Darwin's theory of evolution in 1859, the incredible organization and complexity of living things had no naturalistic or scientific explanation. In fact, human beings were the poster child for the Teleological Argument since it seemed impossible that something as complex and organized as a human being could exist without a designer or maker. (We should, however, acknowledge that Hume had earlier suggested the naturalistic explanation that "matter may contain the source or spring of order originally within itself $\cdots$ ” (Hume, 1779: pp. 20-21).

So let us present the argument without the analogy so as to avoid all of the problems with the analogy: Why do we have a world that is apparently organized and complex? Why does the Universe operate according to laws, such as the laws of gravity and relativity? How did the complexity and organization of human beings come about? These questions call for an explanation, and there are three main candidates.

Possible Explanations for Our Apparently Organized Universe

\begin{tabular}{|c|c|c|}
\hline $\begin{array}{l}\text { God is the Organizer/ } \\
\text { Intelligent Designer/ } \\
\text { Creator. }\end{array}$ & $\begin{array}{l}\text { The world is actually } \\
\text { not very organized. }\end{array}$ & $\begin{array}{c}\text { Naturalistic or Scientific Explanations } \\
\text { can explain the organized complexity } \\
\text { that exists. }\end{array}$ \\
\hline
\end{tabular}

\footnotetext{
${ }^{10}$ Regarding the cosmological argument and possible naturalistic explanations, see Jim Holt, 2012.
} 
The teleological argument asserts that the explanation for the apparent organized complexity of the universe is God. However, this argument ignores the possibilities that the universe is not very well ordered, as demonstrated by the chaos, destruction, evil, misery, and suffering on earth and throughout the universe, and further, that what organization there is may be natural.

Of these choices which is the best? The first choice of God as the creator of an organized universe suffers from several problems. First, this explanation is supernatural, and as discussed, we have no evidence of the existence of anything that is wholly metaphysical/immaterial, as God is presumed to be. Second, at initial glance the universe does not seem perfectly organized as we would expect from a perfect god, and so the second option of a disorganized world has some plausibility.

Third, the first alternative violates Ockham's Razor. The reason we posit God is because we believe that organized complexity needs an explanation, and yet we are left with an even greater organized complexity that we cannot explain, namely, God, and thus have added an entity for which we have no proof. God would not only be so enormously powerful to have created the Universe, but also have a consciousness that the Universe in general does not possess. Moreover, Christians believe that the organizer is perfect as in all-powerful, all-knowing, and all-good. We are therefore left with a similar but much more complex question to answer, namely, how did the organized complexity of God come into being, an entity which is supposed to have two attributes not found in the universe as a whole, namely, consciousness and perfection? We have no answer for this, and this seems to be a much harder question to answer. Indeed, how could an all-powerful, conscious, and perfect being have always existed, or even come into existence? Evolutionary biologist Richard Dawkins explains how this assumption violates the principle of Ockham's Razor to not multiply entities beyond necessity.

If we want to postulate a deity capable of engineering all the organized complexity of the world, either instantaneously or by guiding evolution, that diety must already have been vastly complex in the first place. The creationist, whether a naive Bible-thumper or an educated bishop, simply postulates an already existing being of prodigious intelligence and complexity. If we are going to allow ourselves the luxury of postulating organized complexity without offering an explanation, we might as well make a job of it and simply postulate the existence of life as we know it! * It would be untamed chance if once there was no eye, and then, suddenly, in the twinkling of a generation, an eye appeared, fully fashioned, perfect and whole. This is possible, but the odds against it will keep us busy writing noughts (zeros) till the end of time. The same applies to the odds against the spontaneous existence of any fully fashioned, perfect and whole beings, including - I see no way of avoiding the conclusion—deities (Dawkins, 1986: pp. 451-453).

Science, on the other hand, can explain much of the organized complexity in the world. Dawkins has argued that the laws of physics work a certain way which allow for natural organization (Dawkins, 1986). For example, only smaller items than the size of a hole can fall into that hole. Similarly, genetic mutations that help one survive are more likely to be passed on to the next generation than mutations that will kill you. It just works that way, and does not require further explanation. Additionally, starting with the big bang, the universe unfolded in a certain and explainable way, and life on earth, including human beings, can be explained by a slow, evolutionary process ${ }^{11}$. These naturalistic explanations suffice to explain the organization we encounter in the world, so there is no reason to choose a supernatural explanation.

We should notice here that choices two and three are not exclusive of each other. In fact, it seems that a com-

\footnotetext{
${ }^{11}$ We should note here that theists often attack the naturalistic option by claiming that scientific theories such as evolution do not adequately explain the organization. They argue that many complex physical things found in nature, such as the human eye, are irreducibly complex. By this they mean that their parts are not functional on their own so would have no reason to be passed on to future generations, and it is highly statistically improbable that such complexity would naturally form all at once. As such, we should by default go to the supernatural explanation of God as the origin of such irreducible complexity. This has been referred to as a "God of the Gaps" argument, meaning that when there are gaps in our knowledge we should solve them by turning to the supernatural explanation of God. This argument suffers from several serious problems. First, the argument is based on faulty reasoning: Even if evolution has not yet been able to fully account for the complexity of every specific thing that exists, it does not logically follow that the default position must necessarily be a supernatural God as the source of that complexity. Other naturalistic explanations are possible, including refinements to evolutionary theory. For example, a failure to precisely account for the complexity of every single thing does not mean that evolutionary theory is in any way wrong because intermediate evolutionary steps are sometimes hidden due to our inability to see and know about things which no longer exist but at one time made an earlier version of a thing functional. Second, science is filling in the gaps. Three of the examples often given for irreducible complexity, the eye, the wings of birds, and the immune system, have in fact been demonstrated by scientists to not be irreducible at all. Third, irreducible complexity seems to defeat the default position of God as the explanation for the complexity because God would be a much greater and statistically improbable irreducible complexity for whose origin and existence we have no explanation. See Dawkins, 2006: pp. 144-161.
} 
plete naturalistic answer should combine both of them as follows: A universe with some organization and with some chaos is best explained by scientific principles, not by a perfect God. Let us take human beings, who are far from perfect, as an example. Mutations that help us survive often have other poor consequences for us. For instance, the development of a big brain took away the room needed for our wisdom teeth to grow, the development of walking upright offered some advantages but also created back and foot problems, and the development of an immune system that could better resist malaria made Africans susceptible to getting sickle cell anemia. Evolution, not a good and perfect God who could have created us without these problems, is the best explanation for both the positive changes and their negative side effects, and is evidence of natural organization with attendant disorganization and imperfection ${ }^{12}$.

Antony Flew tells us a parable about an invisible gardener to demonstrate the problem with inferring a supernatural cause from unclear evidence. Two people disagree whether some flowers and weeds in a jungle are tended by a gardener. They watch for a gardener, but never see him. Then they put up an electrified barbed-wire fence and patrol the area with bloodhounds, but no shriek is ever heard, and the dogs never react or growl. Yet the believer in the gardener will not give up his belief, no matter what the evidence. The parable concludes as follows: "At last the Skeptic despairs, 'But what remains of your original assertion? Just how does what you call an invisible, intangible, eternally elusive gardener differ from an imaginary gardener or even from no gardener at all?'” (Flew, 1955: p. 340) This is the challenge put to the theist. Why should we believe in a supernatural organizer, especially when so much of the universe seems to be disorganized, or as Flew might have put it, has so many weeds scattered among the flowers.

\subsection{The Fine-Tuning Argument}

The Fine-Tuning or what I like to call the Statistical Argument builds on the first two arguments for God as follows: There is a big and vast universe (the Cosmological Argument), it appears to be organized through the natural laws (the Teleological Argument), and it further appears particularly fine-tuned for life (the Fine-Tuning/ Statistical Argument). If the natural laws were just a little different, there would be no matter or physical objects in the Universe, and certainly there would not be the necessary conditions for life nor for human beings to exist. The chances that the natural laws would be suitable for life are extremely small. So what caused this statistically improbable "fine-tuning?" The possibilities include the following:

$\begin{gathered}\text { God is } \\ \text { the } \\ \text { fine-tuner. }\end{gathered}$

\begin{tabular}{|c|}
\hline The universe \\
is not \\
fine-tuned \\
for life or \\
advanced life \\
forms since \\
both are rare.
\end{tabular}

\begin{tabular}{|c|}
\hline Multiverse: If there are \\
infinite or countless universes, \\
then some of them would \\
have life, even if most \\
would not. In such a case, \\
universes with life would be \\
inevitable and not fine-tuned.
\end{tabular}
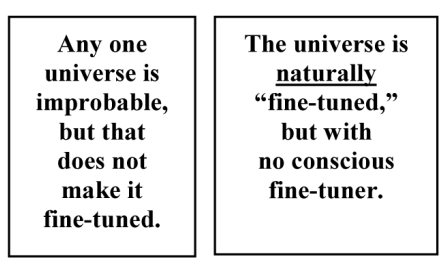

The fine-tuning/statistical argument, which chooses the first alternative of God, is another instance where the naturalistic possibilities are not given their due. First, most of the universe is not fine-tuned for life. The majority of the universe is made up of vast expanses of virtual nothingness that are far too cold to allow for life, and the biggest visible objects, the stars, are far too hot to be habitable. The main candidates for areas where life could exist are the planets, but the vast majority of planets are likewise uninhabitable, and are incompatible with even simple forms of life, let alone with advanced forms of conscious life. Life requires that the planet have just the right chemical composition, right mass, right atmosphere, right orbital properties, right distance from its star, right tilt, and right rotation. Moreover, the star it circles must itself be just the right size, composition, and temperature. Specifically, according to scientists the planet cannot be a gas giant like Saturn or Jupiter; the star must have a life of over a billion years, which many stars do not have, or life will not have enough time to take hold; and the planet's orbit must be very close to circular or there will be too large of a temperature variation on the planet to allow life to survive. Furthermore, planets with low masses cannot maintain an atmosphere, and there-

\footnotetext{
${ }^{12}$ Philip Kitcher makes this point as follows: "If we lapse from the official story for a moment, we have to have some idea about what Intelligence 'wants to achieve'... For if Intelligence has been waiting in the wings throughout the history of life, seizing opportunities as they arise, we know that there are all sorts of things it hasn't done. Apparently Intelligence isn't directed toward eliminating the junk from genomes or removing vestigial structures like the whale's pelvis or generating radically new arrangements for mammalian forelimbs *. For there are really simple genetic problems with respect to which Intelligence seems to be impotent.” (Kitcher, 2007: p. 549).
} 
fore would not be able to have water, nor shield the planet from asteroids or deadly radiation. Additionally, all stars change temperature over time, but only those stars with little variation over long periods of time would provide enough stability for life to take hold—and much longer periods of stability would be required for conscious and advanced life forms to evolve ${ }^{13}$.

Not only is the universe not fine-tuned for life to exist, but it does not appear to be fine-tuned to operate at an optimal level. The assumption of the fine-tuning argument is not simply that life is good, but also that advanced conscious life, such as human beings, is very good, and that is why God would have made the world hospitable to advanced life forms. However, if advanced life forms like human beings are so good, why are they so rare? On our planet, sentient beings that can think and feel pain and pleasure did not arise for billions of years. In fact, our species has only been here for a small fraction of one percent of the time our planet has existed. If conscious life is so good, then why would a creator not have fine-tuned the universe to be habitable for sentient life at a much earlier time, or from its inception? Paul Draper succinctly sums up the problem for theism thusly: "it is more surprising on theism than on naturalism that our universe is not teaming with life, including life much more impressive than human life.” (Draper, 2010: p. 421).

Furthermore, why is nature supposedly "fine-tuned" to have natural disasters that injure and kill conscious beings? Further, why are people born with the sex organs of both sexes, or born with severe physical and mental abnormalities? Additionally, why have over $99 \%$ of the species that have ever existed on earth gone extinct? If sentient life is so good, why does not evolution work so that sentient beings do not eat, harm, and kill each other? Indeed, the so-called fine-tuning does not look so fine when one considers the extensive suffering of living organisms. We could certainly envision a universe much better suited for living beings in general, and sentient beings in particular. As such, the evidence seems to indicate that our universe is anything but fine-tuned—in reality not fine-tuned at all ${ }^{14}$.

Turning to our third choice, why should we expect there to be only one universe? After all, our experience of the world is that things rarely are the only one of their kind, as evidenced by the many and varied stars, galaxies, trees, people, insects, flowers, etc. If there are other universes, then it would not be surprising if some universes had matter and were fit for life while some did not have physical objects or living things. There are several scientific theories regarding other universes, and many scientists believe that universes are quite numerous if not infinite in number ${ }^{15}$. Furthermore, it may be that new universes are continually being added to the multiverse. Additionally, any stable and specific number of universes would seem to require an explanation of why that exact number of universes exists, and this would also apply if there were only one universe. However, if there are an infinite number of universes, no such explanation is needed. Derek Parfit explains this point as follows:

Whether we believe in one or many, we have the question why any Big Bang has occurred. Though this question is hard, the occurrence of many Big Bangs is not more puzzling that the occurrence of only one. Most kinds of thing, or event, have many instances. We also have the question why, in the Big Bang that produced our world, the initial conditions allowed for complexity and life. If there has been only one Big Bang, this fact is also hard to explain, since it is most unlikely that these conditions merely happened to be right. If, instead, there had been many Big Bangs, this fact is easy to explain, since it is like the fact that, among countless planets, there are some whose conditions allow for life. Since belief in Big Bangs leaves less unexplained, it is the better view. ... If all these worlds exist, we can ask why they do. But, compared with most other cosmic possibilities, the All Worlds Hypothesis may leave less that is unexplained. For example, whatever the number of possible worlds that exist, we have the question, "Why that number?"... If ours is the only world, we can ask: "Out of all the possible worlds, why is this the one that exists?" On any version of the Many Worlds Hypothesis, we have a similar question: "Why do just these worlds exist, with these elements and laws?” But if all these worlds exist, there is no such further question (Parfit, 1998).

While it may seem mind-boggling to think there are many, many other universes, the vastness of our own universe might help make it seem more plausible. The latest scientific estimates are that the typical galaxy has 300

\footnotetext{
${ }^{13}$ See Wikipedia on "Planet Habitability."

${ }^{14}$ For an excellent exposition of the many problems with the fine-tuning argument, I recommend the reader to the following writing and later response: Drange, 1998, 2000.

${ }^{15}$ Some physicists/cosmologists who have supported the possibility, if not likelihood, that a multiverse exists include Alexander Vilenkin, Max Tegmark, Lee Smolin, Hugh Everett III, and Brian Greene. For an explanation of Vilenkin's theory of the presence of numerous inflating bubble universes, see Nadis, 2013: pp. 36-41.
} 
billion stars. That is an enormous number of stars. But then consider that scientists have estimated there are 100 billion galaxies-each with on average of 300 billion stars. The enormity of the number of stars cannot really be fully appreciated by the human mind. In fact, the number of stars exceeds the number of grains of sand on all of the beaches on the entire earth. Just start counting the grains of sand on the west coast of the United States, then go up to Canada, then down to Central and South America. Then start counting the grains of sand on the eastern coasts of North, Central, and South America, then go over to Asia, Africa, and Europe, then over to Australia, and finally over to every island over the entire globe. I think we can begin to see that the number of stars in our own universe is staggering. Moreover those stars are spread out over an observable universe of 46 billion light years-another mind-boggling number. When considering the enormity, variation, and complexity in our own universe, it may become a little easier to imagine that there may indeed be many other universes, and those other universes may be as varied as the numerous stars, constellations, and galaxies in our own universe.

Additionally, it is hard to imagine that our expanding universe has a barrier that would prevent it from further expansion. But what is our universe expanding into? It certainly seems plausible that at some point the expansion of our universe will encroach upon the territory of another universe, if it has not already done so, and if some of those other universes are characterized by nothingness we may well have already done so.

Clearly, if there are enough other universes, then we would expect some of them to be compatible with life. Even if relatively few of them would be able to host life, it would be virtually certain that some of them would. So even though the chances of any given universe having life are small, that some universes would have life would be virtually certain, and of course we could only find ourselves in one of the universes compatible with life $^{16}$.

Turning to our fourth option, it may just be a brute fact that there is only one universe, our own. We should notice that any one universe would be statistically unlikely in view of the other myriad of possibilities, but the mere fact that any one universe is unlikely does not mean it needs a supernatural explanation ${ }^{17}$. In fact, this type of statistical unlikelihood is quite common. For example, flip a coin 100 times and record the results and order of each flip. Given all the possible combinations, any resulting combination was highly statistically unlikely, and would undoubtedly take you many lifetimes to duplicate because even if your $1^{\text {st }} 90$ flips were in the exact same order, a highly remote event, if the $91^{\text {st }}$ flip were different from your first $91^{\text {st }}$ flip then you must start over again. However, this high improbability does not require a supernatural explanation since there was $100 \%$ chance that you would flip some combination. Likewise, the chance that you would be born with your exact genetic makeup is statistically small due to all the possibilities or combinations of DNA that you could have inherited from your parents, as well as the random cellular mutations that occur with each conception. We only have to look at how dissimilar siblings are from each other to realize how unique and statistically improbable any given person is. Similarly, if you believe in free will, then the likelihood that I would be here in California writing this paper and having these exact thoughts at this exact time is statistically astronomically unlikely based on the many decisions that could have been decided otherwise. After all, I was born in Chicago, and my first profession was law, not philosophy. These statistical improbabilities, however, do not require a supernatural explanation ${ }^{18}$.

Our last explanatory candidate for the presence of our seemingly fine-tuned universe is the idea that our universe has no conscious fine-tuner but instead is naturally "fine-tuned" for matter and life, at least to some extent. It may even be that the existence of matter and living things is probable, and possibly even inevitable and certain. Just as it is probable that the species which are best suited to their environment will be the ones that survive and exist, it may be that there is something about universes in general, the possible instability of nothingness in particular, or about the nature of a big bang, which naturally make matter and/or life highly likely or even certain to exist. This point was made by Parfit as follows:

This argument's appeal to probabilities can be challenged in a different way. In claiming it to be most improbable that this fine-tuning was a coincidence, the argument assumes that, of possible initial conditions in the Big Bang, each was equally likely to obtain. That assumption may be mistaken. The conditions that al-

\footnotetext{
${ }^{16}$ Some scientists believe that we may be able to find evidence of other universes which have bumped into or otherwise interacted with our own universe. If so, then the theory of other universes would be verifiable.

${ }^{17}$ Parfit explains one version of the brute fact possibility as follows: "Events are random in a stronger sense if they have no cause. That is what most physicists believe about some features of events involving sub-atomic particles. If it is random what reality is like, the Universe not only has no cause. It has no explanation of any kind. This claim we can call the Brute Fact View.” (Parfit, 1998).

${ }^{18}$ For a good discussion of the commonality of apparent statistical improbability, and the lack of necessity to attribute that improbability to a supernatural intelligent source, see Kitcher, 2007: pp. 545-547.
} 
low for complexity and life may have been, compared with all the others, much more likely to obtain. Perhaps they were even certain to obtain (Parfit, 1998).

Ironically, the statistical argument seems to work against the Christian conception of a perfect god because such a god would seem to be statistically astronomically unlikely in view of all the ways the Creator could be, and especially given the evidence that our universe seems to be characterized by no small amount of chaos, evil, misery, and suffering - evidence of anything but perfection.

We should once more consider that choices two through five are not exclusive and several of these options may well be true: Most of our universe is incompatible with life; the universe does not seem fine-tuned at all in view of the facts that life is precarious and difficult; there may be many universes and although the majority of the universes may be incompatible with life we would expect some of them to be hospitable to life, or alternatively, however statistically unlikely the chances of our own particular universe may seem to be, since any one universe which exists would be statistically unlikely given all the possibilities, there is no necessity to resort to a God or other supernatural explanation to explain its existence; and there may be a naturalistic explanation which dictates that matter and life are highly likely to occur in any universe.

Indeed, even if the chances that our universe would have life are small, it is still better than a supernatural explanation. Malcolm Murray explains why:

Whereas in the case of the universe, we have no prior probability of any supernatural agent intentionally designing the universe. So however low the odds of a habitable universe or the first life coming about by chance, it would seem to be still higher than the " 0 " probability we would assign the alternative $\cdots$ Moreover, the fine tuning argument proponents cannot merely rest on getting us to admit that the probability of the preconditions to life is low. They also have to argue that the probability of a supernatural designer is higher. While evolution counts in favor of the prior probability of natural explanations to things, there is no equally probable account of supernatural agency to back the designer hypothesis (Murray, 2010: pp. 86, 88).

Murray further points out that inferring millions or even billions of other universes is not as extreme as inferring a supernatural cause of our own universe because we have no evidence or proof of supernatural beings, but we do have proof of the existence of physical objects, and of at least one universe, our own. Murray explains the mistake of inferring a supernatural cause of the universe as follows: “This isn't quite the same mistake as witnessing only natural events and inferring a supernatural event, mind you, since our inference to cosmoi is a mere increase in number, not in kind.” (Murray, 2010: p. 87) In other words, other cosmoi or universes are still universes, and since we know at least one universe exists this is not nearly as big a leap of faith when compared to the belief in a supernatural being such as God, which would be quite different from anything we know or can prove exists in the universe, if for no other reason that God is supposed to be immaterial and transcendent-not truly a part of the physical world. As such, the probability of numerous other universes would seem to be higher than the probability of a supernatural creator such as God, and the greater the number of other universes there are, the more likely that there would be some universes with the conditions for life ${ }^{19}$.

\subsection{The Argument from the Reliability of Scripture}

The Old and New Testaments contain many references to God, report numerous actions purportedly performed by God, and record various conversations between God and people. The theist offers these texts as evidence or proof of God's existence.

There are, however, obvious problems with blindly accepting ancient texts in general, and Christian religious texts in particular. First, few Christians would accept the Hindu account of many gods, although numerous Hindu texts refer to these gods, record conversations with these gods, and report on the actions of these gods, similar to how the Bible refers to one god. The reason a Christian would reject a Hindu text is because they would recognize that those texts were written by superstitious people in superstitious times long before there was mod-

\footnotetext{
${ }^{19}$ We should note here that some versions of the Statistical (Fine-Tuning) Argument try to show much more than there is a very powerful creator of the universe, which is all that the Cosmological and Teleological Arguments attempt to substantiate. Some proponents of the fine-tuning argument claim that the fine-tuning or statistical improbability mandate that God is perfect. God's goodness is demonstrated by the fact that God made this universe compatible with life. However, even though parts of our universe are compatible with life, this hardly shows that God is all-good. If life is so good, then why would an all-good creator not create habitable conditions much more prevalent than they are?
} 
ern science to help them understand the world. However, the same holds true for Christian texts.

Furthermore, there are good reasons to doubt the accuracy and truth of the ancient Biblical texts, and it therefore follows that we are warranted in viewing Biblical references to metaphysical things such as God and heaven and hell as especially untrustworthy. Just taking the New Testament, historians have wide disagreement about virtually everything regarding the reliability of its books. A widely accepted view among historians is that none of the books were written until decades after Jesus' death. Moreover, many if not most scholars agree that the authors of the Gospels were not eyewitnesses to the actual events in Jesus' life. Indeed, New Testament scholar Bart Ehrman has made a strong case that many of the New Testament books are in fact forgeries-meaning that the authors of the texts tried to deceive others into believing that they were Jesus' disciples or from his inner circle, when in fact they were people who lived decades later and were trying to lend credibility to their faith and church (Ehrman, 2011).

More specifically, bases for doubting both the Old and New Testament are their internal inconsistencies and contradictions, historical inaccuracies, and the numerous stories and claims that contradict accepted and wellsubstantiated modern scientific views.

Addressing the inconsistencies in Scripture, many people do not realize that there are two different stories about the creation of the universe in the Old Testament's book of Genesis. In the initial story, God first created the animals, and then he created man and woman, apparently creating man and woman at the same time. (Genesis 1:24-27) In the second version, however, the order of creation on the sixth day is first, man, then the animals, and lastly woman (Genesis 2:7, 18-22).

A second example from the Old Testament is regarding the burial of Aaron. In Numbers 33:38 (also in Numbers 20:22-29) the Bible says that "Aaron the priest ascended Mount Hor at the command of the LORD, and died there $\cdots$ " while in Deuteronomy 10:6 it says that "the Israelites marched to Moserah. Aaron died there and was buried there $\ldots, 20$.

The New Testament is not immune to similar discrepancies between its different books. For example, there are at least four different versions of the precise words that appear on a sign put over Jesus after he is crucified (Compare Matthew 27:37, Mark 15:26, Luke 23:38, and John 19:19); There are competing versions for who was Jesus' $1^{\text {st }}$ Apostle and the subsequent order of the Apostles who next joined and followed Jesus (Compare Luke 5:1-10 and John 1:35-45); There are different stories of the fig tree (See Mark 11:12-26, and Luke 13:6-8); In two versions of the parable of the Vineyard Owner some of the master's slaves are killed (Matthew 21:33-36, Mark 12:1-6) while a third version states that they were not killed, but rather all were only beaten (Luke 20:9-12); Jesus' last words vary in different books (See Mark 15:34 and Matthew 27:46 vs. Luke 23:46); In one book Jesus seems to have been crucified on the day of preparation for Passover (John 13:1 and 19:13-16), but in the other books he is crucified after the Passover dinner. (See for example Matthew 26:17-27:50); And there are various versions about who went to the tomb to see Jesus after the crucifixion, and who actually saw Jesus thereafter. (Compare John 20:1-20; Matthew 28:1-10; Mark 16:1-10; and Luke 24:1-24).

In addition to inconsistencies between different Biblical stories, numerous historians have doubts as to whether many of the stories actually took place. First, many stories in the Bible seem to be a retelling of older stories from earlier legends. For example, the story of Moses' birth (See Exodus 2:2-6, 9-10) seems strikingly similar to the much earlier story of the King of Sargon, found on Neo-Babylonian tablets which date to the third millennium $\mathrm{BC}^{21}$. Although the stories are not identical, their similarities are hard to ignore. In each the mother had a baby in secret, had to let the baby go, put the baby into a basket that was sealed with tar, the baby went adrift into a river, and the baby was discovered by the person who ended up becoming his foster parent. Both stories involve babies that would become leaders. It is such an unusual story involving a leader that it would be natural to suspect that the Biblical story was borrowed from this earlier story, and is not what really occurred.

Likewise, the claim of the miraculous virgin conception of Jesus appears borrowed from earlier religious traditions from around the world. For example, the following are some of the numerous examples of Gods who

\footnotetext{
${ }^{20}$ All quotations to the Old Testament come from Plaut, 1981, and all quotations from the New Testament come from Holman Bible Publishers, 2001.

${ }^{21}$ Here is the story of Sargon as set forth on Neo-Babylonian tablets: "Sargon, the mighty king, the king of Agade, am I. My mother was a priestess, my father I never knew. The brothers of my father inhabited the hills. My city is Azupiranu, lying on the bank of the Euphrates. My priestess mother conceived me, in secret she gave birth to me. She set me in a basket of rushes, with bitumen she closed my door. She cast me into the river, but it did not overwhelm me. The river bore me up and carried me to Akki the drawer of water. Akki the irrigator lifted me out as he dipped his bucket. Akki the irrigator took me as his son and reared me. And for 55 years I exercised kingship.” (Colless, 2013).
} 
were the result of virgin births: The Egyptian God Horus, The Aztec God Huitzilopochtli, the Greek God Erechtheus, the Roman God Mars, and according to a famous Chinese myth, Qi was conceived when his mother stepped in a giant footprint left by the supreme diety Shangdi (Gannon, 2013).

Not only do some of the stories in the Bible seem to be borrowed from earlier stories, but there is a real question whether some of the major occurrences in the Bible ever occurred. For example, recent scholars have begun to question whether the Jews were ever actually slaves in Egypt, and whether the Jews really wandered in the desert for 40 years. According to Exodus 12:40, the Israelites were slaves in Egypt for 430 years. In spite of this, there is no archaeological or documentary evidence outside of the Bible to verify this. As stated by two archaeologists:

We have no clue, not even a single word, about the early Israelites in Egypt: neither in monumental inscriptions on the walls of temples, nor in tomb inscriptions, nor in papyri. Israel is absent-as a possible foe of Egypt, as a friend, or as an enslaved nation (Finkelstein \& Silberman, 2001: p. 60).

Moreover, Exodus indicates that more than one million people wandered in the desert for over forty years, yet there has been no archaeological or other evidence found to verify this. Thirty eight of the forty years were supposedly spent in one location, Kadesh-Barnea, and although the location of Kadesh-Barnea has been identified, and in spite of many expeditions and digs in the area, no artifacts or other evidence has been found indicating the presence of Jews in this area at that time.

Lastly, the words of the Bible contradict modern science in many ways. For example, the Bible's claim that the universe is less than 7000 years old contrasts with accepted scientific claims that it is billions of years old; the Biblical claim that everything was created by God in the first six days is contrary to what is accepted as scientific fact about the ongoing creation of stars, planets, and species over billions of years; and the Biblical claim that on the sixth day of creation, all of the species, including human beings, were created, contradicts evolution and the overwhelming scientific evidence pointing to the relatively recent emergence of our own species. Further, claims of miracles, which are suspensions of the natural laws, are contradictory to modern science.

So we see that there are many reasons to disbelieve parts of the Bible, and it seems this would especially hold true for its metaphysical claims of God's existence. Let's look at a charting of this argument:

In the Bible, there are numerous references to God, accounts of conversations with God, and descriptions of God's actions, including God's miracles. What is the best explanation for this?

Possibilities:

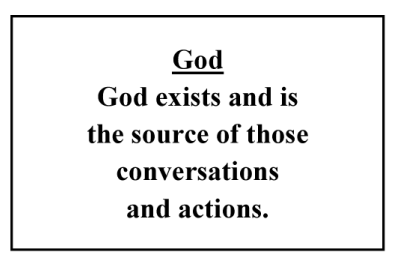

\begin{tabular}{|c|}
\hline Mistaken Superstitious Beliefs \\
Both the Old and New Testament were written long \\
ago by superstitious people in superstitious times and \\
are unreliable-as evidenced by their inconsistencies \\
and historical and scientific inaccuracies.
\end{tabular}

Of the two choices, which is the most believable? It seems to be the second choice since it does not rely upon the supernatural. Further, since Christians would not believe the religious texts of other religions which contain different metaphysical views than their own, the impartial observer should likewise not readily believe these ancient Christian Scriptures.

\subsection{The Argument from Miracles}

Miracles are, by definition, a suspension of the natural laws that can only be explained by supernatural powers. People often misuse the term, as when, for example, they claim that it is a miracle when someone who is very ill gets well, as when a cancer goes into remission. This would not, however, qualify as a miracle because we know that the body has an immune system that allows it to repair and protect itself. Although we have a gap in our knowledge in that we do not yet know which people will be able to overcome any given serious illness, it is likely that in the future genetic research will allow physicians and scientists to do so with reasonable accuracy.

Although an unexplained suspension of the natural laws lends some support for the existence of supernatural powers as the source of the suspension, it alone would not prove the existence of God, nor of any perfect being. 
It seems that we would need some clear communication from God that God performed the miracle, but then again, if we had a clear, confirmed and verifiable communication from God then we would not need the miracle to verify God's presence. Moreover, we have already discussed in the previous section that the fact that miracles have been written about in ancient books does not make them credible.

One obvious problem with ancient accounts of miracles is that ancient peoples did not understand the natural laws well enough to be able to distinguish a natural occurrence from a supernatural one. We know that some things that ancient people thought were miracles can today be explained by science. For instance, some ancient people interpreted a total eclipse of the sun as a miracle, but we now know that it happens on those rare occasions when the moon passes in front of the sun in such a way that it fully hides the appearance of the sun for several minutes. A second example is taken from Exodus in the Old Testament, and involves the seemingly miraculous parting of the Red Sea. Although it is questionable whether this ever really occurred, there are currently several scientific theories how there could have been a natural parting of the Red Sea to allow Moses and the Jews to safely cross $^{22}$.

David Hume also notes the almost perfect symbiosis between the people who are motivated to lie about miracles in order to improve their own status and the majority of people who so want to believe in miracles that they are too quick to place their trust in others:

The many instances of forged miracles, and prophesies, and supernatural events, which, in all ages, have either been detected by contrary evidence, or which detect themselves by their absurdity, prove sufficiently the strong propensity of mankind to the extraordinary and the marvelous, and ought reasonably to beget suspicion against all relations of this kind $\cdots$ But what greater temptation than to appear a missionary, a prophet, an ambassador from heaven (Hume, 1777: pp. 79,86)?

So let us now chart the Argument from Miracles: Throughout history, there have been many reports of miracles, which are suspensions of the natural laws. What is the best explanation of these so-called miracles?

Possible Explanations:

\begin{tabular}{|c|}
\hline$\frac{\text { Supernatural }}{\text { Explanation }}$ \\
\hline $\begin{array}{c}\text { They are } \\
\text { miracles } \\
\text { performed } \\
\text { by God. }\end{array}$ \\
\hline
\end{tabular}

\begin{tabular}{|c|} 
Scientific Explanation \\
They are not miracles at all, \\
but rather, can be explained as \\
part of the natural laws, which \\
superstitious people of ancient \\
times did not understand.
\end{tabular}

\begin{tabular}{|c|}
\hline Deceit \\
People have selfish \\
motives to falsely \\
claim that they \\
created or witnessed \\
a miracle. \\
\hline
\end{tabular}

\begin{tabular}{|c|}
\hline Gullibility \\
People want to \\
believe in the \\
miraculous, so do \\
so too readily and \\
without proof.
\end{tabular}

Which of these explanations are most likely to be true? Hume argued that choices 2-4 could together account for all of the claimed miracles ${ }^{23}$. Moreover, there are reasons to not choose the first option of God: First, it is a supernatural explanation, and we have no evidence of the existence of immaterial supernatural things or beings. Second, it violates Ockham's Razor because we have added an entity, God, for whose existence we have no explanation. Third, most Christians do not believe in the claimed miracles of other religions-likely believing they are superstitious beliefs held by superstitious peoples, and yet give their own religion a free pass. Fourth, no mi-

\footnotetext{
${ }^{22}$ For example, in 2010, a team at the National Center for Atmospheric Research in Boulder, Colorado argued that when a fortuitous blend of wind, water depth, and bottom contours occur, the parting of a sea can occur. At the right spot, such as a sharp bend where a shallow river meets a coastal lagoon, wind moving across the bend could push water both upstream and downstream, exposing the bottom. When the sustained winds finally die down, water returns from both directions to cover the muddy land bridge. The phenomenon is known as wind setdown. Modeling results that the team conducted of a section of the eastern Nile Delta suggest that it could have had the right characteristics some 3000 years ago to provide a temporary wind-swept land bridge for a group fleeing Egypt (as reported by Spotts, 2010).

${ }^{23} \mathrm{Hume}$ famously argues that we know the natural laws because they are the uniform experience of all people-which means that the natural laws are supported by an overwhelming amount of evidence. Therefore the claim of a miraculous exception is always based on lesser evidence when compared to the abundance of evidence that nature works a certain way all of the time (see Hume, 1777: pp. 76-77). There are arguably two related problems to this argument, namely, his claim seems to be both unfalsifiable and circular: Unfalsifiable because no matter what the evidence for a supernatural cause of the event, Hume will never allow it to be enough to count as a true supernatural miracle and circular because Hume assumes that the natural laws do not and cannot have exceptions, and therefore he would interpret any seemingly unexplainable event in a way that confirms his prior belief. In spite of these potential problems, when we fashion Hume's points into alternatives to supernatural explanations by using the Inference to the Best Explanation, Hume's overall argument provides strong support for going with naturalistic explanations to explain what seemed to be unexplainable to primitive, superstitious people who did not have the benefits of modern science.
} 
racle has ever been witnessed and confirmed by a large group of educated people today, and has certainly not been verified by any group of prior skeptics or non-believers. It is curious that God's miracles would be performed only in ancient times and witnessed by only ancient or superstitious people, as Hume points out in the following passage:

For first, there is not to be found, in all history, any miracle attested to by a sufficient number of men, of such unquestioned good-sense, education, and learning, as to secure us against all delusion in themselves; $\cdots$ It forms a strong presumption against all supernatural and miraculous relations, that they are observed chiefly to abound among ignorant and barbarous nations; or if a civilized people has ever given admission to any of them, that people will be found to have received them from ignorant and barbarous ancestors, who transmitted them with the inviolable sanction and authority, which always attend received opinions $\cdots$ It is strange, a judicious reader is apt to say, upon the perusal of these wonderful historians, that such prodigious events never happen in our days (Hume, 1777: pp. 78-80).

\subsection{The Argument from Religious Experience}

Many people claim to communicate with God, or otherwise experience God, perhaps by feeling God's presence. But are they really experiencing God? There are reasons to believe they are mistaken.

First, we should notice that our experiences are psychological, meaning, they are in our mind. They are necessarily private, and unless we are hooked up to a brain scan, nobody else knows what we are thinking or experiencing. We also know that many people experience things that have no correspondence to what is actually taking place in the outside world. They may be merely imagining, or hallucinating, or day-dreaming, or wishing, etc. Scientists have shown that we construct our experiences, and scientists have strong evidence which shows that we have the ability to construct experiences that do not correspond with anything that has occurred in the outside world. Moreover, we tend to construct experiences that accord with our preexisting beliefs. As such, it is not surprising that the Christian experiences a single God, the Hindu experiences many gods, and the Buddhist or atheist do not experience any Gods. The experience of God seems to be circular in that our experience may well be constructed by our imagination to merely reinforce what we have been taught and already believe. These same points were made by Steven Katz when analyzing cross-cultural mystical experiences when he states that we must recognize the need to ask the following fundamental question:

"What does the Christian bring to his experience and how does it affect that experience, and what does the Hindu bring to his experience and how does it affect that experience?” ... Beliefs shape experience, just as experience shapes belief $\cdots$ the mystic brings to his experience a world of concepts, images, symbols, and values which shape as well as colour the experience he eventually and actually has (Katz, 1978: pp. 30,46).

Second, the many people who claim they are have experienced God seem to have had quite different experiences, and a fair assessment of those experiences do not clearly point to an experience of the same thing or of God. One person hears a voice, another feels a presence, a third person pictures God with a human-like appearance, and a fourth person believes they are engaging in telepathic communications with God. Their experiences are so substantially different that it is difficult to conclude that they are having an experience of the same thing at all, and so indeterminate and amorphous that it is difficult to conclude it is an experience of God.

Third, we know that our sensory experiences can be verified by others. If you and I are in the same room, we should see and hear essentially the same, or at least quite similar, things. The problem with claims about metaphysical things, however, is that they cannot be verified in the way that sensory experiences can. A theist who claims he or she is communicating with God would likely be met with skepticism by others who are in that same room but not having the same or a similar experience. Notice that it is not merely that the non-believer does not communicate with God, but they also do not and seemingly cannot witness the supposed communications between God and the theist, even if they have a desire to do so. Does the theist who experiences God have special powers that the religious skeptic does not have? This appears doubtful since human beings are fundamentally similar in body structure and basic abilities.

In short, the fundamental problem with experiences of God is that they are beyond the senses, untestable, unverifiable, and unfalsifiable- the same problems that metaphysical claims in general suffer from. Let us now chart the Argument from Religious Experience: 
People believe that they experience God in various ways. Many claim to feel God's presence. Others claim that they communicate with God, and that God speaks to them and gives them advice and direction. People often claim to experience God although other people in the same room are not having a similar experience. What is the best explanation for such claims and experiences?

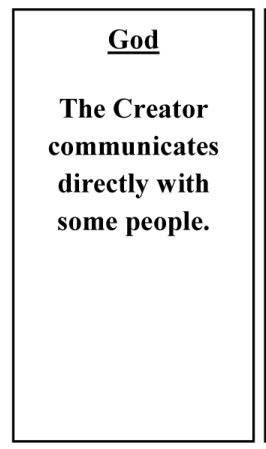

\begin{tabular}{|c|}
\hline Vague, Different \\
Experiences \\
Those who claim \\
to experience God \\
have amorphous \\
and dissimilar \\
experiences \\
which do not point \\
to God or even to \\
the same source.
\end{tabular}

\begin{tabular}{|c|}
\hline Wish Fulfillment \\
People construct or \\
imagine such \\
experiences \\
because they want \\
there to be a God \\
who can answer \\
their prayers, \\
protect and aid \\
them.
\end{tabular}

\begin{tabular}{|c|}
\hline Confirmation Bias/ \\
\hline Circular Beliefs \\
People already \\
believe in God, \\
and then construct \\
and interpret their \\
experiences \\
accordingly to fit \\
their preexisting \\
beliefs.
\end{tabular}

\begin{tabular}{|c|}
\hline Deceit \\
People want to \\
feel important \\
or special, or be \\
granted special \\
status, and thus \\
claim to have an \\
experience that \\
they have not had.
\end{tabular}

Choices 2-5 can when considered together can arguably explain all of peoples' so-called experiences of God. Moreover, there are reasons to disbelieve the first alternative of God: Not only is there no evidence of the existence of non-physical entities such as God, but also there is no way to test, verify, or confirm that a person's alleged experience of God corresponds to anything that actually exists outside of one's mind. Furthermore, a monotheist would not trust a polytheist's belief in many gods although the polytheist makes a similar claim of being able to experience and communicate with their gods. The problem with this argument is summed up nicely by Paul Draper: "Finally, experiences apparently of God are no doubt more to be expected if God exists than if there is no God, but various facts about their distribution are more likely on naturalism, such as the fact that many people never have them and the fact that those who do have them almost always have either a prior belief in God or extensive exposure to a theistic religion.” (Draper, 2010: p. 421).

\subsection{The Ontological Argument}

The Ontological Argument attempts to prove God's existence with the use of reason or logic alone, and usually without any direct appeal to our experiences of the world. There are several versions of this argument, but they all basically claim that because we can think of a perfect God, such a God must necessarily exist ${ }^{24}$. If the argument rests purely on a logical as opposed to an experiential foundation, then it is probably not a viable candidate to be analyzed by inference to the best explanation because the logic is either valid and sound or it is not. However, I think that some and perhaps the best versions of the argument, such as one put forth by Descartes, do consider our experiences of the world, and these versions can appropriately be analyzed as inferences to the best explanation.

We should first note that the Cosmological, Teleological, and Statistical Arguments for God's existence, and the Argument from Miracles, attempt to show that a very powerful creator or entity exists, but do not in themselves attempt to prove that such an entity is perfect. As such they make much weaker claims than the Ontological Argument does. In general, the stronger the claim, the easier it is to find a flaw because it alleges much more that must be defended. Because the Ontological Argument makes the stronger claim that not only is there a powerful creator of the Universe, but also that the creator is perfect, as in omnipotent, omniscient, and all-good, it has much more to prove and defend.

Why would anyone argue that just because we can think of a perfect God that such a God must necessarily exist when we know that we can think of many things which do not exist, such as mermaids, Santa Claus, and

\footnotetext{
${ }^{24}$ I have always thought there were several things quite peculiar with this argument. For one, when there is doubt whether something exists, normally we would expect someone to at first try to show that something like that exists, and then to show the specific nature, attributes, and characteristics of that thing. For example, both the Cosmological and Teleological Arguments, and also the Argument from Miracles, argue for the existence of a powerful creator that can be called God, but do not in themselves attempt to show that God is perfect. More needs to be done beyond these arguments to substantiate the creator's perfection. The Ontological Argument, on the other hand, seems to have reversed the process in that the theist begins with trying to prove that a perfect being must exist, and then concludes that God therefore exists. As such, it attempts to prove the characteristics of God either before or simultaneously with the attempt to prove God's existence.
} 
unicorns? Descartes' version of the ontological argument, which is contained in his Third Meditation ${ }^{25}$, attempts to answer this. Descartes claims that the idea of a perfect God could not have come from himself/Descartes. But why not? Descartes says he did not acquire the idea through his senses, and therefore the idea must have come from God who placed the idea in him. In other words, Descartes does not believe that he could think of infinite perfection on his own since he has never experienced it. Why not? Descartes does not answer this, but it seems that he believes that there is something very different about imagining perfection than imagining mermaids and Santa Claus. We might use Hume here to help Descartes and conclude that the idea of mermaids and Santa Claus comes from combining things we have previously experienced, but combining the excellent things we have experienced in the world would still not give us the idea of full perfection, or so Descartes seems to believe. But is this so hard to imagine?

It seems to me that not only is it possible to have a general thought about a perfect creator, but it is very natural to desire to do so and to actually do so. After all, we experience many limited perfections in the world, and often strive for perfection. For instance, some of us witnessed the Miami Dolphins record a perfect record in the 1972 football season, and watched the perfect records achieved by the UCLA basketball teams coached by John Wooden in 1964, 1967, 1972, and 1973. People strive for perfection all the time. Moreover, we witness people do good things, judges administer justice, leaders conquer nations, and scientists acquire knowledge about the world. It seems only natural to imagine an all-good, all-powerful, and all-knowing entity, and it certainly is comforting to imagine that such an entity will ensure that good people will be eventually rewarded. It appears clear, at least to me, that we do not have to have experienced a perfect being to be able to imagine one, at least in a very general and imprecise sense.

Let us chart the ontological argument: How is it that we can we think of a perfect being if we have never experienced such a perfect being?

\section{Possible Explanations:}

God put this idea into our minds, so God must exist.
It is natural to imagine things that do not
exist, and this is certainly true when it
comes to good things and even perfection.

Which of the two choices seems most likely? First, we should notice that this so-called proof of a perfect God seems contrary to the supposed evidence of God's works, namely, our world, which appears to be anything but perfect. Certainly if we observe imperfect creations we are not warranted to conclude that those imperfections were created by a perfect being. At most, we would be warranted to attribute the imperfections in our world to an imperfect creator. David Hume made this point as follows:

First, by this method of reasoning, you renounce all claim to infinity in any of the attributes of the Diety. For, as the cause ought only to be proportioned to the effect, and the effect, so far as it falls under our cognizance, is not infinite; what pretensions have we, upon your suppositions, to ascribe that attribute to the Divine Being (Hume, 1779: Part 5, p. 41)?

That this world seems to be very different than the creation we would expect by a perfect God is highlighted by recent statistical data which indicate that most human conceptions end in the natural death of the fetus, and throughout history until $1800 \mathrm{AD}$ over 50\% of people died as children-most dying either in infancy or before

\footnotetext{
${ }^{25}$ The version of Descartes' Ontological Argument that I am referring to states in relevant part as follows: "So there remains only the idea of God; and I must consider whether there is anything in the idea which could not have originated in myself. By the word 'God' I understand a substance that is infinite, eternal, immutable, independent, supremely intelligent, supremely powerful, and which created both myself and everything else (if anything else there be) that exists. All these attributes are such that, the more carefully I concentrate on them, the less possible it seems that they could have originated from me alone. So from what has been said it must be concluded that God necessarily exists $\cdots$ For how could I understand that I doubted or desired — that is, lacked something — and that I was not wholly perfect, unless there were in me some idea of a more perfect being which enabled me to recognize my own defects by comparison? $\cdots$ Altogether then, it must be concluded that the mere fact that I exist and have within me an idea of a most perfect being, that is, God, provides a very clear proof that God indeed exists. It only remains for me to examine how I received this idea from God. For I did not acquire it from the senses; $\cdots$ The only remaining alternative is that is innate in me, just as the idea of myself is innate in me. And indeed, it is no surprise that God, in creating me, should have placed this idea in me to be, as it were, the mark of the craftsman stamped on his work $\cdots$ ” (Descartes, 1640: pp. 31,35).
} 
the age of 5 from natural causes. This hardly seems like the design of a perfect creator ${ }^{26}$. A similar example recently presented itself to me when my then-pregnant wife endured terrible pain during childbirth. Or we could consider the fact that until recent times so many women died in childbirth. The length, complications, difficulties, pain, and death associated with pregnancy and childbirth seem quite contrary to what a perfect creator would create, and can more easily be explained with Darwinian and other naturalistic explanations.

A second problem with going with the first choice of God is that we have no evidence of beings that can exist without physicality.

Third, the ontological argument seems doomed from its inception because it attempts to prove the existence of something on the basis of logic and reasoning alone. However, logic's role and abilities are limited to telling us if an argument is valid or invalid, and pertains to how propositions and claims fit together or are consistent or inconsistent with each other, but not whether something exists. We know of existence because of our senses, through which we experience the world. Without our senses, it is difficult to see how we could know about the existence of anything outside of our own minds. We can imagine things exist, but then with our senses we need to investigate whether they actually exist. Reasoning alone does not seem capable of revealing what actually exists ${ }^{27}$.

Fourth, although on first glance the idea of a perfect being, i.e. a being that is all-powerful, all-knowing, and all-good and just, seems coherent, some people have questioned this, especially when it is utilized in conjunction with the Christian concepts of Heaven, Hell, and the Devil ${ }^{28}$. For example, many Biblical passages state that one's actions are what matter for purposes of God's judgment as to whether one will ultimately reside in Heaven or $\mathrm{Hell}^{29}$. If so, then any punishment that is eternal would seem to far exceed any amount of wrongdoing that one could do in one lifetime. A Hell of perpetual burning with intense suffering, and forever, would certainly surpass any possible finite number of crimes. This seems to be the opposite of justice, and in fact makes God appear both malicious and evil.

Further, we should notice that there appears to be only two ultimate choices for God to make- to send souls to either Heaven or to Hell (purgatory being only a temporary stop before going to Heaven). From this it follows that those people just above a certain line will be just good enough to go to Heaven, and go forever, and people just below that same line will go to Hell, and forever. But these two people are almost identical. Those just above and below the line have almost no differences in behavior, and yet one is rewarded forever and the other is sent to an eternity of torture. Again, this appears anything but just, and is inconsistent with a good and just God. Notice that God could have created a myriad of places to send souls, but Christianity limits the options to only a Heaven and a Hell. As such, God's actions would violate a basic tenet of justice, namely, proportionality - the notion that we should not treat significantly similar persons in radically different ways.

Alternatively, other Biblical passages indicate that it is not actions that determine one's ultimate fate, but the belief in God and faith in Jesus' redemptive power (i.e., committing one's life to God and Christ) are what determine whether someone goes to Heaven or Hell ${ }^{30}$. However, here it seems that God would be both unjust and cruel to send someone who has otherwise led an exemplary moral life to Hell forever on the basis of a mistaken belief, especially when the mistake seems both understandable and has no ill will behind it.

In a similar fashion, it seems hard to reconcile the Devil with a just God. Why would God create such an evil

\footnotetext{
${ }^{26}$ For the citations to studies and expert opinions which provide this statistical evidence, see Paul, 2009: pp. 125-149. Paul argues that an allgood God would have prevented so many innocent fetuses and children from these premature natural deaths.

${ }^{27}$ As Descartes has taught us, the one exception to this statement would seem to be our own existence. Arguably through our reasoning alone we can know we exist as thinking beings.

${ }^{28}$ For example, some people have argued that the idea of an all-powerful God is internally inconsistent because God cannot make a rock he cannot lift, nor can he create a circle which has four sides (because at that point it becomes another object such as a square or a rectangle), nor make killing innocent people for fun into a moral action, nor forget anything he did. Others have maintained that if human beings have free will, then God could not possibly see our future actions, so God is not all-knowing. Nonetheless, I am not sure that either of these assertions are actually serious problems for the theist because we could define "all-powerful" as anything that God could logically do, and define "all-knowing" as anything God could possibly know given that He created free-will creatures. I think, however, there are problems with the idea of perfection when it comes to the belief that God is all-good, and also thereby all-just. First, when determining the right or correct action, is it the consequences that matter the most, is it the type of action that matters the most, or is it something in between? When determining what is just, what would be the criteria? If someone kills another person, what would be the just punishment or result? I am not sure that there ever could be clear criterion for justice and goodness, and if not, then it seems that to claim God is all-good and just is in reality an empty claim.

${ }^{29}$ The following New Testament passages support the position that one's actions are what determine their ultimate fate of either Heaven or Hell:John 5:28-29, Romans 2:6-8, James 2:14, 24, 26, Matthew 5:28-29, Matthew 12:36, Jude:1:7, and Revelations 21:8.

${ }^{30}$ The following New Testament passages support the position that one's fate or final residence after death is determined by one's beliefs, as opposed as to their actions:Galatians 2:11, Romans 9:31-32, Mark 3:28-29, John 3:36, John 14:6, Acts 10:43, Titus 3:5.
} 
being, and why does God not stop the Devil from his misdeeds by either killing him or taking away his powers ${ }^{31}$ ? After all, when we encounter a serial murderer, we either put him to death or restrain him in jail forever. Why does God not act similarly to protect us? Furthermore, it seems unjust to allow the Devil to tempt good people, and then deliver the ultimate punishment to those same people who give in to temptation. In fact the real culprits would be the Devil for his actions, and God for not limiting and/or eliminating the Devil's actions. While giving in to temptation might well be worthy of punishment, a much lesser punishment than an eternity in Hell would certainly be appropriate for those who are led astray by the wrongdoing of others.

To summarize, since the world seems imperfect as it is filled with apparent chaos, as well as destruction, injustice, misery, and suffering, it seems questionable if not unlikely that the creator was perfect. Moreover, the idea of a perfect being almost certainly does not make sense when viewed in conjunction with the Christian beliefs in Heaven, Hell, and the Devil. Furthermore, the assertion that we could prove anything actually exists because we can think of it seems implausible since we know about the existence of things only from experiencing them or their clear effects in the world. Lastly, we have no physical, scientific, or testable evidence that anything metaphysical and non-physical exists, so it seems hard to believe that such a thing must necessarily exist. As such, the best explanation of why we can at least abstractly think of a perfect being is that we have experienced limited perfections in the past, and it is natural for us to desire such a perfect being and thus imagine that being to actually exist.

\section{Conclusion}

We have seen that the many arguments for God's existence seem to discount or ignore available naturalistic explanations. I have argued that these naturalistic explanations should be favored over supernatural ones. Paul Draper captures the essence of my argument: "The naturalistic explanation is in each case better than the theistic explanation because of its metaphysical modesty — other things being equal, it is better to subtract by elimination or reduction than to add a supernatural person to one's ontology, especially since naturalistic explanations have successfully replaced supernatural ones so many times in the past.” (Draper, 2010: pp. 422-423).

Indeed, the theist, whether they are Christian or otherwise, must rely on unseen, unsensed, untestable, and unverifiable entities or forces that have little to no possibility to ever be seen, sensed, tested, or verified. This is the nature of metaphysical beliefs, and why so many philosophers have disparaged metaphysics in general. The English philosopher A. J. Ayer said this about the metaphysician:

Must he not begin, as other men do, with the evidence of the senses? And if so, what valid process of reasoning can possibly lead him to the conception of a transcendent reality? Surely from empirical premises nothing whatsoever concerning the properties, or even existence, of anything super-empirical can legitimately be inferred (Ayer, 1936: p. 1220).

Kai Nielsen encapsulates the difficulty in ever going with a supernatural explanation:

At the core of the theistic belief there is the metaphysical belief in a reality that is alleged to transcend the empirical world. It is the metaphysical belief that there is an eternal, ever-present, creative source and sustainer of the universe. The problem is how it is possible to ever know or even reasonably believe that such a reality exists $\cdots$ (Nielsen, 2010: p. 522).

We have seen that all of the arguments for the existence of God can be couched as Inferences to the Best Explanation. When charting these arguments, we cannot help but recognize that there are naturalistic explanations available. It has been the contention of this paper that if there are naturalistic explanations then they should be favored over supernatural explanations such as God, if for no other reason that the existence of such an invisible God cannot be tested, measured, or verified in any way, unlike the naturalistic explanations.

\section{References}

Ayer, A. J. (1936). Language, Truth and Logic. In L. Pojman (Ed.), Ch. 40. Classics of Philosophy, Volume II: Modern and

\footnotetext{
${ }^{31}$ In fact, in Revelation it appears that the Devil will ultimately be punished and defanged of his powers by God: "The Devil who deceived them was thrown into the lake of fire and sulfur where the beast and the false prophet are, and they will be tormented day and night forever and ever." (Revelation, 20: 10). Why does God not do this much sooner? Why does God allow so many good people to be misled and tempted into sin by the Devil? God's inaction seems anything but righteous and just, and his eternal condemnation of those weak souls seems to be extraordinarily cruel.
} 
Contemporary (pp. 1218-1225). New York: Oxford University Press.

Colless, B. E. (2013). The Empire of Sargon.

Dawkins, R. (1986). The Blind Watchmaker. New York: W.W. Norton \& Company.

Dawkins, R. (2006). The God Delusion. New York: Houghton Mifflin Company.

Drange, T. (1998). Nonbelief and Evil: Two Arguments for the Nonexistence of God (pp. 378-386). Amherst, NY: Prometheus Books.

Drange, T. (2000). Response to Parrish on the Fine-Tuning Argument. Philosophia Christi, 2, 61-67.

Draper, P. (2010). Cumulative Cases. In C. Taliaferro, P. Paul Draper, \& P. Quinn (Eds.), Ch. 49. A Companion to Philosophy of Religion (2nd ed.). West Sussex: Wiley-Blackwell Publishing.

Ehrman, B. (2011). Forged: Writing in the Name of God-Why the Bible's Authors Are Not Who We Think They Are. New York: HarperOne Harper Collins.

Finkelstein, I., \& Silberman, N. (2001). The Bible Unearthed (p. 60). New York: Free Press.

Flew, A., \& MacIntyre, A. (1955). New Essays in Philosophical Theology. In L. Pojman (Ed.), Philosophy of Religion: An Anthology (4th ed., pp. 339-340). Belmont, CA: Wadsworth, Division of Thomson Learning.

Gannon, M. (2013). 6 Miracle Birth Stories beyond Jesus. Live Science, December 23.

Hawking, S., \& Mlodinow, L. (2010). The Grand Design. New York: Bantom Books.

Holman Bible Publishers (2001). New Testament, Holman Christian Standard Bible.

Holt, J. (2012). Why Does the World Exist? New York: Liveright Publishing Corporation, Division of W.W. Norton \& Co.

Hume, D. (1777). An Enquiry Concerning Human Understanding, Section X, Part II. Hackett Publishing Company.

Hume, D. (1779). Dialogues Concerning Natural Religion, Part II. New York: Barnes \& Noble.

Kant, I. (1783). Prolegomena to Any Future Metaphysics. In L. Pojman (Ed.), Ch. 24. Classics of Philosophy, Volume II: Modern and Contemporary. New York: Oxford University Press.

Katz, S. (1978). Language, Epistemology and Mysticism. In S. Katz (Ed.), Mysticism and Philosophical Analysis. New York: Oxford University Press.

Kitcher, P. (2007). Living with Darwin: Evolution, Design, and the Future of Faith. In P. Peterson, W. Hasker, B. Reichenbach, \& D. Basinger (Eds.), Philosophy of Religion (4th ed., pp. 542-550). New York: Oxford University Press.

Murray, M. (2010). The Atheist’s Primer. Chapter 20: Non-Falsifiability (pp. 168-179). Ontario: Broadview Press.

Nadis, S. (2013). Starting Point. Discover, September, 36-41.

Nielsen, K. (2010). Naturalistic Explanations of Theistic Belief. In C. Taliaferro, P. Draper, \& P. Quinn (Eds.), Ch. 61. A Companion to Philosophy of Religion (2nd ed., pp. 519-525). West Sussex: Wiley-Blackwell Publishing.

Paley, W. (1802). Natural Theology, or Evidences of the Existence and Attributes of the Diety Collected from the Apearances of Nature. In L. Pojman (Ed.), Ch. 22. Classics of Philosophy, Volume II: Modern and Contemporary (pp. 667-669). New York: Oxford University Press.

Parfit, D. (1998). Why Anything? Why This? The London Review of Books, 24-27 (Part 1), 22-25 (Part 2).

Paul, G. (2009). Theodicy's Problem: A Statistical Look at the Holocaust of the Children, and the Implications of Natural Evil for the Free Will and Best of All Worlds Hypotheses. Philosophy \& Theology, 19, 125-149. http://dx.doi.org/10.5840/philtheol2007191/27

Plaut, W. (1981). The Torah: A Modern Commentary. New York: Union of American Hebrew Congregations.

Rene Descartes, R. (1640). The Philosophical Writings of Descartes (Vol. II). Cambridge: Cambridge University Press.

Schick Jr., T., \& Vaughn, L. (2011). How to Think about Weird Things: Critical Thinking for a New Age (6th ed., pp. 161181). New York: McGraw Hill.

Shermer, M. (2006). The Political Brain. Scientific American, 295, 36. http://dx.doi.org/10.1038/scientificamerican0706-36

Spinoza, B. (1677). Ethic, Prop. XV. In L. Pojman (Ed.), Ch. 18. Classics of Philosophy, Volume II: Modern and Contemporary (pp. 533-577). New York: Oxford University Press.

Spotts, P. (2010). Moses Parting of the Red Sea: Is There a Physical Explanation? Christian Science Monitor, September 21.

Steinhardt, P., \& Turok, N. (2002). A Cyclic Model of the Universe. Science, 296, 1436-1439.

http://en.wikipedia.org/wiki/Planetary_habitability

http://dx.doi.org/10.1126/science.1070462 
Scientific Research Publishing (SCIRP) is one of the largest Open Access journal publishers. It is currently publishing more than 200 open access, online, peer-reviewed journals covering a wide range of academic disciplines. SCIRP serves the worldwide academic communities and contributes to the progress and application of science with its publication.

Other selected journals from SCIRP are listed as below. Submit your manuscript to us via either submit@scirp.org or Online Submission Portal.
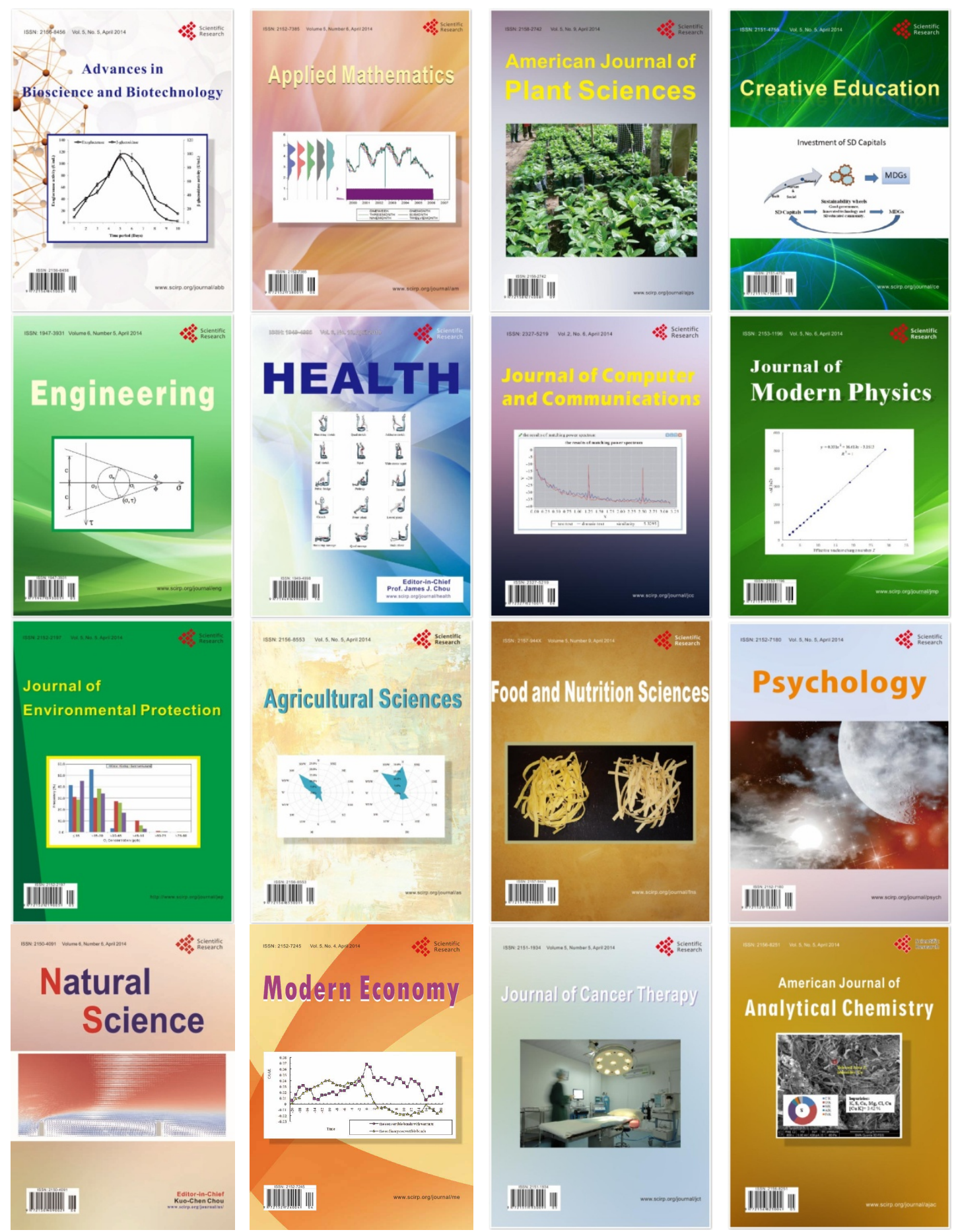